\title{
Ovarian Mucinous Cystadenocarcinoma
}

National Cancer Institute

\section{Source}

National Cancer Institute. Ovarian Mucinous Cystadenocarcinoma. NCI Thesaurus. Code C4026.

An invasive cystic adenocarcinoma arising from the ovary. It is characterized by the presence of malignant glandular epithelial cells which contain intracytoplasmic mucin. The malignant cells invade the ovarian stroma and the cystic spaces contain mucoid material. In a minority of cases both ovaries are involved by the tumor. The prognosis for stage I tumors is excellent. Patients with metastases usually have a poor prognosis. 